\title{
MRI Study to Evaluate Anatomic Oblique Lumbar Interbody Fusion Corridor in Indian Population
}

\author{
Sharvil Gajjar ${ }^{1}$, Amit Jhala ${ }^{1}$, Shivam Kiri ${ }^{1}$, Manish Mistry ${ }^{2}$ \\ ${ }^{1}$ Department of Spine Surgery, Chirayu Spine and Orthopaedic Hospital, Ahmedabad, Gujarat, India \\ ${ }^{2}$ Department of Orthopedic Surgery, Chirayu Spine and Orthopaedic Hospital, Ahmedabad, Gujarat, India
}

Received: July 2, 2021

Revised: August 16, 2021

Accepted: August 17, 2021

Corresponding Author:

Amit Jhala, MS, DNB

Department of Spine Surgery,

Chirayu Spine and Orthopaedic

Hospital, 203-204 Chirayu

Complex, Narayan Nagar Rd, Paldi,

Ahmedabad, Gujarat 380007, India

Tel: +91-9825040172

E-mail:acjhala@gmail.com
Objective: The anatomic corridor is defined by different studies in the western population but the exact corridor for the Indian population is never been studied. Objective of the study was to define anatomical corridor for preoperative assessment of Oblique Lumbar Interbody Fusion (OLIF) in the Indian population.

Methods: We selected imaging data from 180 adults (90 males and 90 females) who underwent MRI. The windows studied at L1-2 to L4-5 levels were vascular window, bare window, psoas major window, and operative window. The bare window was further analysed by dividing it into three groups. Group 1 with no window, group 2 with 0 to $5 \mathrm{~mm}$ window, and group 3 with more than $5 \mathrm{~mm}$. Statistical analysis was carried out by unpaired t-test.

Results: The bare window was largest at L1-2 $(1.29 \pm 0.53 \mathrm{~cm})$ and smallest at L4-5 $(0.79 \pm$ $0.52 \mathrm{~cm})$. The psoas major window was largest at $L 3-4(1.24 \pm 0.38 \mathrm{~cm})$ and smallest at L1-2 $(0.45 \pm 0.47 \mathrm{~cm})$. The operative window was largest at $L 3-4(2.4 \pm 0.47 \mathrm{~cm})$ and smallest at $L 4-5$ $(1.72 \pm 0.67 \mathrm{~cm})$. In $10.56 \%$ of patients at $L 4-5$, there was no bare window and OLIF cannot be performed in these patients.

Conclusion: Bare window gradually decreases from $L 12$ to $L 45$ levels. In the majority of patients at L12, L23, and L34 there is adequate bare window and OLIF can be safely performed. In $10.56 \%$ of patients, the bare window for performing OLIF does not exist at L45 and OLIF may not be feasible in these patients.

Key Words: Oblique lumbar interbody fusion, Oblique corridor, Bare window, Anatomical corridor

\section{INTRODUCTION}

The patients with symptomatic lumbar canal stenosis were historically treated with decompression by laminectomy and the option of fusing the spinal segments has evolved gradually with the further understanding of lumbar segment instability [1]. Spinal fusion is required for alleviation of pain and stabilization in the affected unstable segment and a variety of approaches can be used to achieve it. Open spine surgery has higher morbidity, slower recovery, more likely to develop postoperative pain, higher probability of post-operative infections, muscular atonia, and longer hospital stay [2]. Minimally Invasive Spine (MIS) surgery has evolved gradually since it introduced tubular retractor in 1997 and with subsequent technological advancement has become the preferred choice over conventional open surgery [3]. This gave rise to MIS retroperitoneal approaches. These approaches obviate the need to disrupt the posterior paraspinal muscle damage and provides

Copyright (C) 2021 Korean Minimally Invasive Spine Surgery Society

This is an Open Access article distributed under the terms of the Creative Commons Attribution Non-Commercial License (http://creativecommons.org/licenses/by-nc/4.0/) which permits unrestricted non-commercial use, distribution, and reproduction in any medium, provided the original work is properly cited. 
exposure to the intervertebral disc through a lateral approach which allows the insertion of a cage far larger in size than what is achievable through the posterior approach [4]. The possibility of insertion of a cage having a broader dimension allows increasing the chances of fusion, get the maximum possible segmental lordosis, and better sagittal alignment. It also provides the required decompression of the spinal canal indirectly by jacking up the disc space, distracting the facet joints, and stretching up the ligamentum flavum [5].

MIS Transpsoas lateral approaches have a high incidence of lumbar plexus injury and to avoid that OLIF approach gained popularity which takes surgical window between major vessels and psoas major muscle from L2 to L5 $[6,7]$. There is wide variation in vascular anatomy of the major vessels in form of the width of the vessels, course, and bifurcation [8,9]. Similarly, there are anatomical variations in the psoas major muscle in form of thickness, bulk, and orientation [9-11]. Hence the surgical corridor for OLIF between L2 to L5 has large variations. If the procedure is performed where there is no surgical access window for performing OLIF, there is a possibility of vascular injury [12]. Hence it is imperative to define each corridor to exactly evaluate different spaces. Western studies are done to find out this surgical corridor on cadaveric specimens and CT scans [6,13-16].

OLIF is an emerging technique in India and there is no anatomical research about the Indian population to guide the surgeons regarding the approach. Indian population is structurally different compared to the western population. Currently, imaging anatomical data regarding the Indian population concerning OLIF is not available in the literature. Our study aims to examine and calculate surgical corridors of OLIF to find the feasibility of OLIF procedure at different levels in the lumbar spine from L2 to L5 in the Indian population. This is the first study in the Indian population for oblique corridor analysis. We analyzed operative windows for oblique approach through MRI, which is widely available, cheap and as it is required to be done for diagnostic purposes, it does not require the patients to undergo any further investigation.

\section{MATERIALS AND METHODS}

We selected imaging data from 180 adults who underwent MRI Lumbosacral spine. The sample size included 90 males and 90 females with a maximum age of 84 years and minimum age of 18 years and the average age was 49 years. Coronally aligned patients with back pain with or without radicular pain were included and patients with age less than 18 years, trau- matic, tumorous or spondylodiscitis cases, prior lumbar or retroperitoneal surgery, vertebral abnormalities such as hemivertebrae, spina bifida, and spinal deformities such as scoliosis or kyphosis were excluded. We used axial section at each disc level L1-2, L2-3, L3-4, and L4-5. All the windows to approach the intervertebral disc were measured on the left side as that was the common side of the approach. The anatomical parameters measured of different windows are shown in Figure 1.

\section{Vascular Window}

This is the area occupied by the major vessels in front of the disc space. This area is avoided in the OLIF approach. It is measured by the distance from the left border of the abdominal aorta or left iliac vessels to the median sagittal plane.

\section{Bare Window}

It is the bare area between the major vessels and the anterior border of the psoas major muscle which is the surgical corridor for OLIF procedure. It is measured by the distance from the left

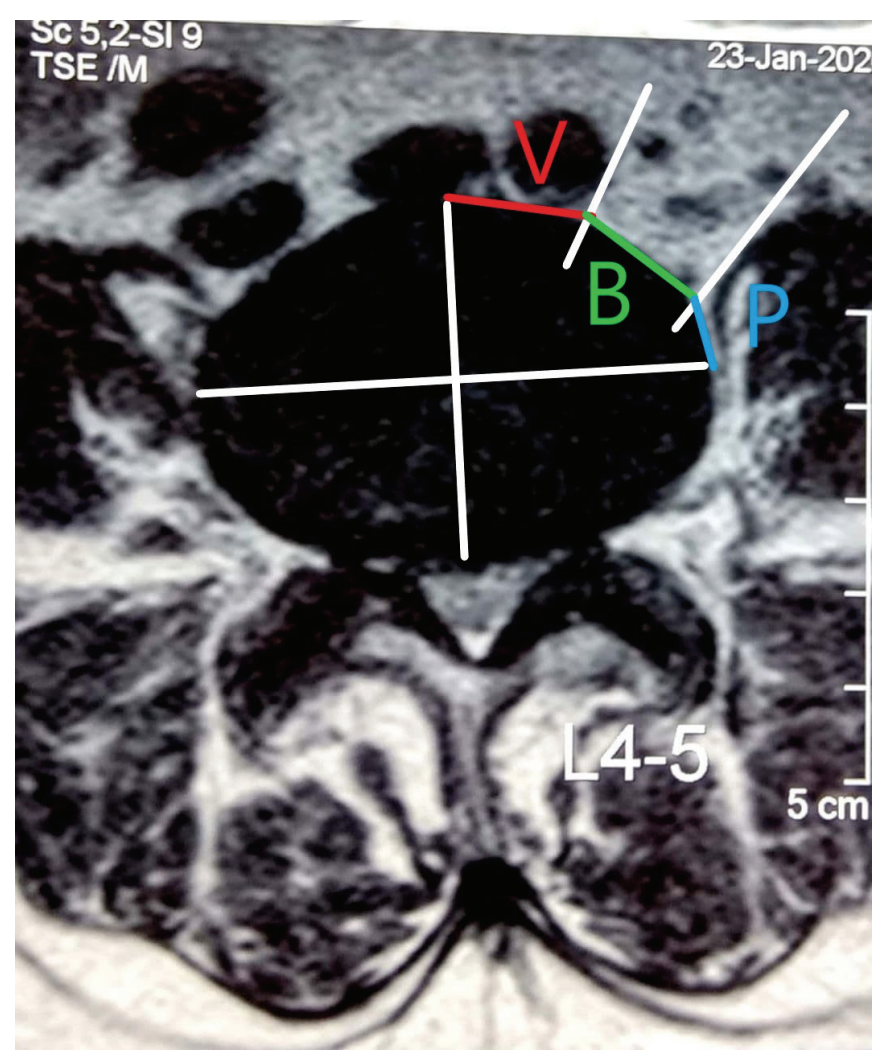

Figure 1. Axial section at the L4-5 level. V: vascular window, B: bare window, $P$ : psoas major window, operative window=Bare window $(\mathrm{B})+$ Psoas major window $(\mathrm{P})$. 
margin of the major vessels and the anterior border of the psoas major muscle.

\section{Psoas Major Window}

It is the portion of the intervertebral disc which is anterior to the mid transverse plane, and is covered by psoas major muscle. This area can be used for performing OLIF with retraction of the psoas major muscle. This was measured by distance from the anterior border of the psoas major muscle to point at the mid transverse plane of the intervertebral disc.

\section{The Operative Window}

This is the area clinically used for performing OLIF. It is a combination of bare window and psoas major window.

\section{Percentage of Bare Window}

This is the percentage ratio of the bare window concerning the operative window. It is measured by Bare window/Operative window $\times 100$.

\section{Percentage of Psoas Major Window}

This is the percentage ratio of psoas major window concern- ing the operative window. It is measured by Psoas window/ Operative window $\times 100$.

\section{RESULTS}

Mean values of different windows in centimeters $(\mathrm{cm})$ at each level with Standard Deviation (SD) are shown in Table 1. The vascular window was largest at L4-5=1.84 $( \pm 0.56) \mathrm{cm}$ and smallest at L3-4=1.18 $( \pm 0.37) \mathrm{cm}$. The bare window was largest at L1-2=1.29 $( \pm 0.37) \mathrm{cm}$ and smallest at L4-5=0.79 $( \pm 0.52)$ $\mathrm{cm}$. Psoas major window was largest at L3-4=1.24 $( \pm 0.38) \mathrm{cm}$ and smallest at L1-2 $=0.45( \pm 0.47) \mathrm{cm}$. The operative window was largest at L3-4=2.40 $( \pm 0.47) \mathrm{cm}$ and smallest at L4-5=1.72 $( \pm 0.67) \mathrm{cm}$.

As shown in Table 2 there were significant differences between males and females at L1-2 and L4-5 vascular windows ( $p$-value $<0.05$ ) while at middle sections i.e. L2-3 and L3-4 difference between the two genders was not significant at the vascular window. While in middle sections L2-3 and L3-4, there was a significant difference between the bare windows of males and females ( $\mathrm{p}$-value $<0.05)$ and there was no significant difference at L1-2 and L4-5 of the bare window.

Width of the left psoas major muscle (Figure 2) at all levels in the mid-frontal plane is shown in Table 3.

Psoas major width was widest at L4-5 followed by L3-4, L23 , and L1-2 and their values are $3.34( \pm 0.79) \mathrm{cm}, 2.16( \pm 0.78)$

Table 1. Mean values of different windows at each level in centimeters

\begin{tabular}{lcccc}
\hline Windows & $\mathrm{L} 1-2(\mathrm{SD})$ & $\mathrm{L} 2-3(\mathrm{SD})$ & $\mathrm{L3}-4(\mathrm{SD})$ & $\mathrm{L4}-5(\mathrm{SD})$ \\
\hline Vascular window & $1.42( \pm 0.36)$ & $1.19( \pm 0.38)$ & $1.18( \pm 0.37)$ & $1.84( \pm 0.56)$ \\
Bare window & $1.29( \pm 0.53)$ & $1.25( \pm 0.50)$ & $1.15( \pm 0.48)$ & $0.79( \pm 0.52)$ \\
Psoas major window & $0.45( \pm 0.47)$ & $1.00( \pm 0.39)$ & $1.24( \pm 0.38)$ & $0.93( \pm 0.41)$ \\
Operative window & $1.74( \pm 0.44)$ & $2.24( \pm 0.48)$ & $2.40( \pm 0.47)$ & $1.72( \pm 0.67)$ \\
\hline
\end{tabular}

SD: standard deviation.

Table 2. Statistical differences in the windows between males and females

\begin{tabular}{|c|c|c|c|c|c|}
\hline Windows & Gender & L1-2 (SD) & L2-3 (SD) & L3-4 (SD) & L4-5 (SD) \\
\hline \multirow{3}{*}{ Vascular window } & Male & $1.52( \pm 0.37)$ & $1.22( \pm 0.37)$ & $1.20( \pm 0.40)$ & $1.74( \pm 0.59)$ \\
\hline & Female & $1.32( \pm 0.32)$ & $1.16( \pm 0.38)$ & $1.17( \pm 0.37)$ & $1.92( \pm 0.56)$ \\
\hline & $p$-value & 0.000 & 0.30 & 0.59 & 0.03 \\
\hline \multicolumn{6}{|l|}{ Operative window } \\
\hline \multirow[t]{3}{*}{ Bare window } & Male & $1.22( \pm 0.47)$ & $1.13( \pm 0.50)$ & $1.01( \pm 0.48)$ & $0.76( \pm 0.54)$ \\
\hline & Female & $1.36( \pm 0.52)$ & $1.36( \pm 0.49)$ & $1.29( \pm 0.44)$ & $0.82( \pm 0.49)$ \\
\hline & $p$-value & 0.059 & 0.002 & 0.000 & 0.46 \\
\hline \multirow[t]{3}{*}{ PSOAS major window } & Male & $0.59( \pm 0.47)$ & $1.19( \pm 0.31)$ & $1.47( \pm 0.29)$ & $1.08( \pm 0.40)$ \\
\hline & Female & $0.32( \pm 0.44)$ & $0.81( \pm 0.37)$ & $1.01( \pm 0.31)$ & $0.78( \pm 0.37)$ \\
\hline & $p$-value & 0.000 & 0.000 & 0.000 & 0.000 \\
\hline
\end{tabular}


$\mathrm{cm}, 1.30( \pm 0.61) \mathrm{cm}, 0.51( \pm 0.52) \mathrm{cm}$ respectively. There was a significant difference between males and females at all levels (p-value<0.05).

Table 4 shows the percentage of different windows compared to the operative window at all levels.

From the above measurements, we found that if we use the criteria of $1 \mathrm{~cm}$ as the minimum operative corridor for the bare window required to perform the OLIF procedure then OLIF cannot be performed in most of the Indian patients at L45 as the average bare window available is only $0.79 \mathrm{~cm}( \pm 0.52)$ and in $68.9 \%$ patients, the bare window is less than $1 \mathrm{~cm}$ at L4-5. It is also obvious that if the bare window is ' $0 \mathrm{~cm}$ ' then it is very risky to do OLIF because of the risk of vessel damage but if the space is more than $0.5 \mathrm{~cm}$ it can be accessed with some retraction of the psoas muscle. So, we subdivided bare window into three groups considering ease of doing surgery as shown in Table 5.

Group 1: no space between major vessels and psoas major (0 mm) (Figure 3)

Group 2: Bare window is between 0-5 $\mathrm{mm}$ (Figure 4)

Group 3: Bare window more than $5 \mathrm{~mm}$ (Figure 5)

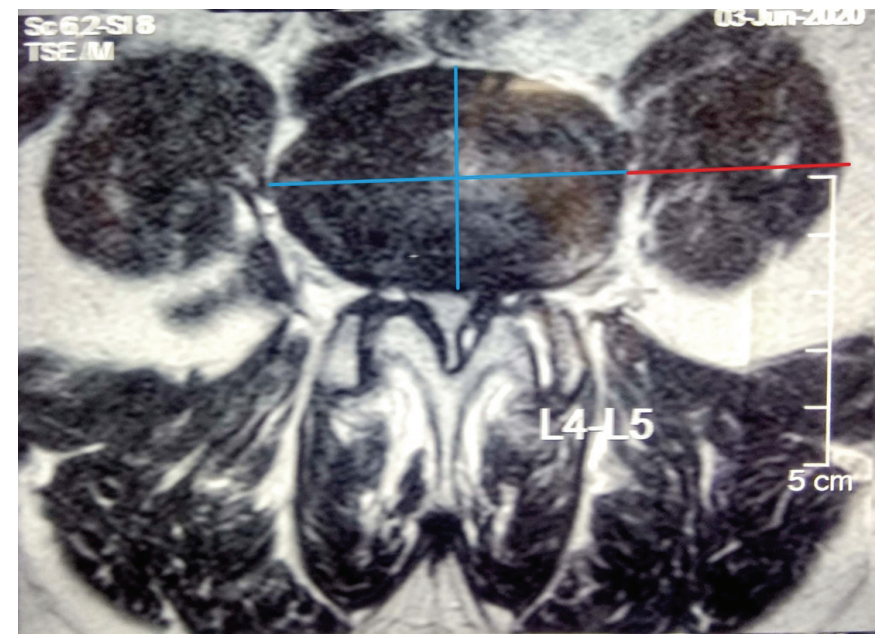

Figure 2. Red line indicates psoas major width in the mid frontal plane.
Group 1 patients where OLIF is extremely risky to be performed, Group 2 patients where OLIF can be performed with some retraction of the psoas muscle. $5 \mathrm{~mm}$ was taken as an arbitrary measurement because the Jamshidi needle or the smallest dilator of the retractor can be docked directly over the disc space. Surgeons with some experience can access this space. Group 3 patients where space is more than $5 \mathrm{~mm}$ it is easy to perform this procedure.

With this subgroup analysis of bare window as shown in Table 5, $10.56 \%$ patients at L45, $1.12 \%$ patients at L34, $0.56 \%$ patients at $\mathrm{L} 23$, and $2.78 \%$ at $\mathrm{L} 12$ were in Group 1 where it is not feasible to perform OLIF procedure.

We also tried to find out if instead of taking a bare window

Table 4. Percentage of operative window from L1-L5

\begin{tabular}{lccc}
\hline Levels & $\begin{array}{c}\text { \% of vascular } \\
\text { window }\end{array}$ & $\begin{array}{c}\text { \% of bare } \\
\text { window }\end{array}$ & $\begin{array}{c}\% \text { of psoas major } \\
\text { window }\end{array}$ \\
\hline L1-2 & 81.6 & 74.14 & 25.86 \\
L2-3 & 53.12 & 55.8 & 44.64 \\
L3-4 & 49.17 & 47.92 & 51.67 \\
L4-5 & 106.98 & 45.93 & 54.07 \\
\hline
\end{tabular}

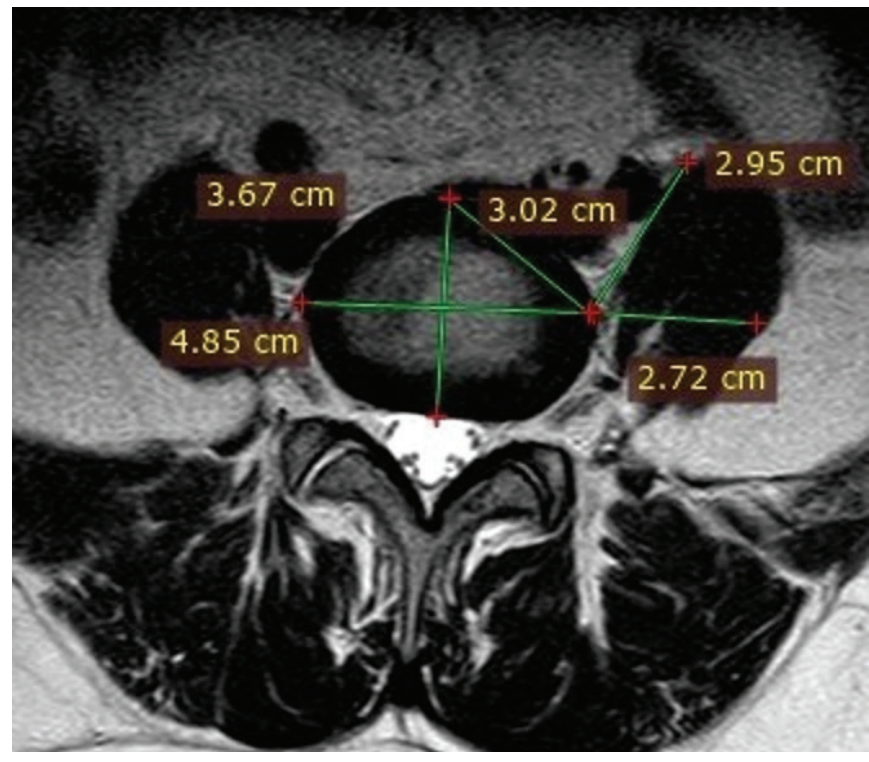

Figure 3. No space between major vessels and psoas major.

Table 3. Mean width of psoas major in mid-frontal plane in centimeters

\begin{tabular}{|c|c|c|c|c|}
\hline Psoas major width & L1-2 (SD) & L2-3 (SD) & L3-4 (SD) & L4-5 (SD) \\
\hline All & $0.51( \pm 0.52)$ & $1.30( \pm 0.61)$ & $2.16( \pm 0.78)$ & $3.34( \pm 0.79)$ \\
\hline Male & $0.72( \pm 0.56)$ & $1.67( \pm 0.51)$ & $2.58( \pm 0.70)$ & $3.67( \pm 0.73)$ \\
\hline Female & $0.30( \pm 0.37)$ & $0.94( \pm 0.46)$ & $1.74( \pm 0.63)$ & $3.01( \pm 0.72)$ \\
\hline p-value & 0.000 & 0.000 & 0.000 & 0.000 \\
\hline
\end{tabular}


of $1 \mathrm{~cm}$ as criteria, if the operative window of $1 \mathrm{~cm}$ is taken as criteria then OLIF can be performed after retracting the psoas up to the middle of the vertebral body. We divided the operative window into two groups depending on the width $<1 \mathrm{~cm}$ and $>1$

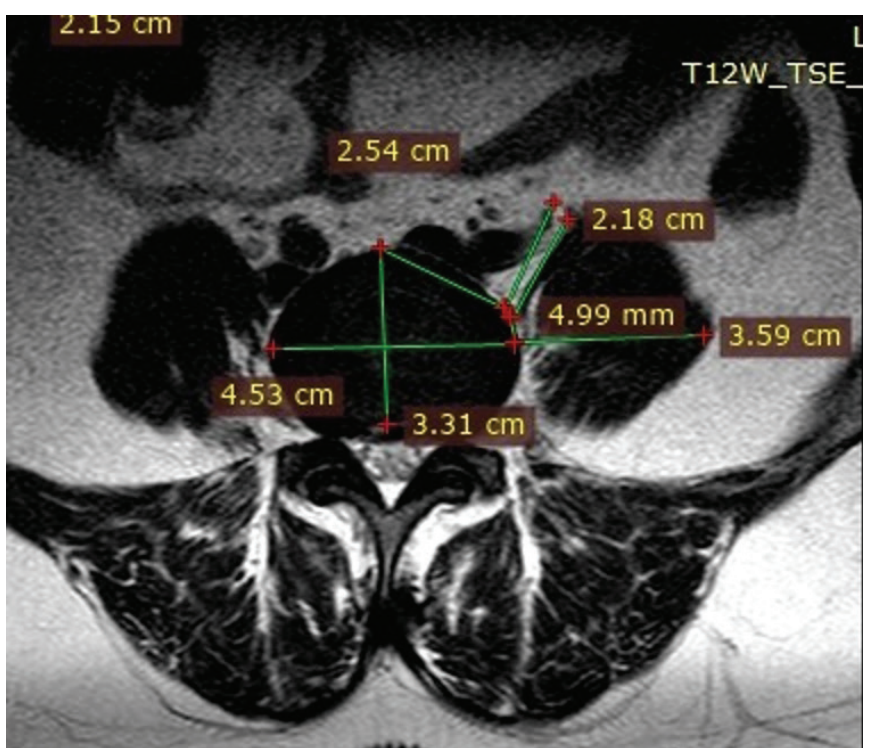

Figure 4. Bare window between 0 to $5 \mathrm{~mm}$

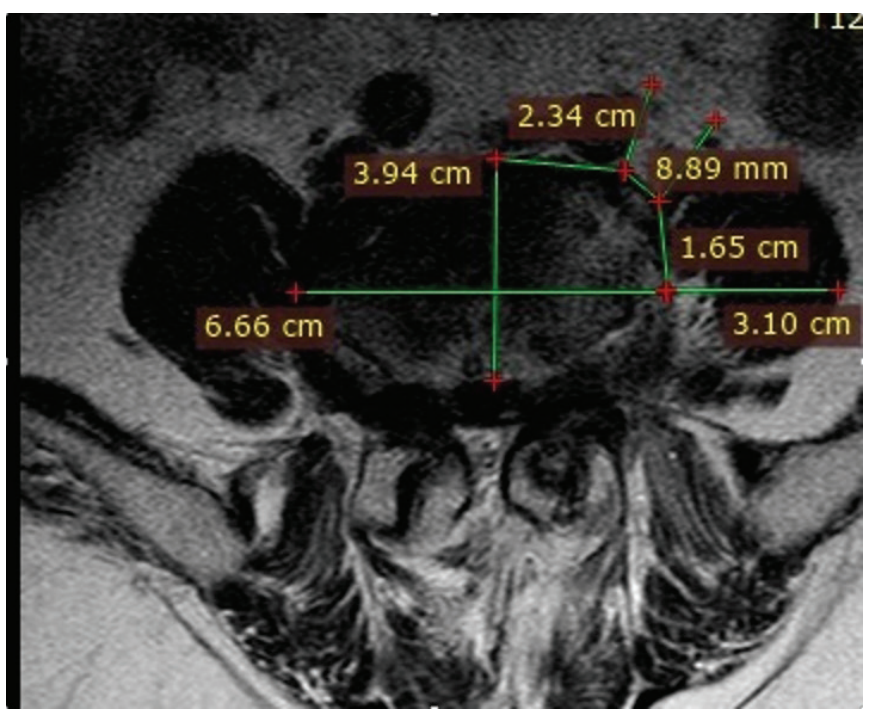

Figure 5. Bare window more than $5 \mathrm{~mm}$. cm for safe approach for OLIF from L1 to L5 and are shown in Table 6 . It shows that operative window $<1 \mathrm{~cm}$ is $10.55 \%$ patients at $\mathrm{L} 45,0 \%$ patients at $\mathrm{L} 34,0.55 \%$ patients at $\mathrm{L} 23$ and $3.33 \%$ patients at L12. Therefore, considering both the criteria of the bare window and operative window, $10.56 \%$ of patients at L45 have bare window $0 \mathrm{~cm}$, and $10.55 \%$ of patients at L45 have an operative window of $<1 \mathrm{~cm}$, it is not feasible to perform OLIF in Indian patients.

\section{DISCUSSION}

We observed in our study that vascular window is maximum at L4-5 $(1.84 \pm 0.56 \mathrm{~cm})$ followed by L1-2 $(1.42 \pm 0.36 \mathrm{~cm}), \mathrm{L} 2-3$ $(1.19 \pm 0.38 \mathrm{~cm})$ and $\mathrm{L} 3-4(1.18 \pm 0.37 \mathrm{~cm})$. The vessel width is gradually narrowing from L1-2 to L3-4. At L4-5 there is vessel bifurcation which causes an increase in the vascular window. Psoas major window was maximum at L3-4 $(1.24 \pm 0.38 \mathrm{~cm})$ followed by L2-3 $(1 \pm 0.39 \mathrm{~cm}), \mathrm{L} 4-5(0.93 \pm 0.41 \mathrm{~cm})$ and L1-2 $(0.45 \pm 0.47 \mathrm{~cm})$. The psoas muscle is thinnest at the L1-2 level with a gradual increase in the musculature caudally. Bare window is maximum at L1-2 $(1.29 \pm 0.53 \mathrm{~cm})$ followed by L2-3 $(1.25 \pm 0.50 \mathrm{~cm}), \mathrm{L} 3-4(1.15 \pm 0.48 \mathrm{~cm})$ and L4-5 $(0.79 \pm 0.52 \mathrm{~cm})$. At L45 the bare window is minimum, and this is obvious as gradually the great vessels are coming laterally from L12 going down and psoas major muscle is gradually become bulkier starting from L12 up to L45. Hence it is relatively easier to operate at L3-4 and L2-3 levels and need to be careful while operating at L4-5 level because of the narrow operative window due to the larger size of the vascular window and psoas window making the bare window small. This has been shown in the measurements of the vascular window and psoas major window. The operative window which is a combination of bare window and psoas major window is maximum at L3-4 $(2.40 \pm 0.47 \mathrm{~cm})$ followed by L2-3 $(2.24 \pm 0.48 \mathrm{~cm}), \mathrm{L} 1-2$ $(1.74 \pm 0.44 \mathrm{~cm})$, and $\mathrm{L} 4-5(1.72 \pm 0.67 \mathrm{~cm})$. This window is important during surgery as after docking on the bare window the psoas major muscle can be retracted giving larger access to the disc space. So the operative window is a combination of bare window and psoas major window.

Table 5. Bare window subgroup analysis

\begin{tabular}{|c|c|c|c|c|c|c|c|c|c|}
\hline \multirow{2}{*}{ Levels } & \multicolumn{3}{|c|}{ Bare window ' 0 ' mm } & \multicolumn{3}{|c|}{ Bare window 0 to $5 \mathrm{~mm}$} & \multicolumn{3}{|c|}{ Bare window $>5 \mathrm{~mm}$} \\
\hline & Male & Female & Total & Male & Female & Total & Male & Female & Total \\
\hline L1-2 & 2 & 3 & $5(2.78 \%)$ & 4 & 2 & $6(3.36 \%)$ & 84 & 85 & 169 (93.89\%) \\
\hline L2-3 & 1 & 0 & $1(0.56 \%)$ & 7 & 1 & $8(4.48 \%)$ & 82 & 89 & $171(95 \%)$ \\
\hline L3-4 & 2 & 0 & $2(1.12 \%)$ & 7 & 4 & $11(6.61 \%)$ & 81 & 86 & $167(92.78 \%)$ \\
\hline L4-5 & 12 & 7 & $19(10.56 \%)$ & 17 & 18 & 35 (19.44\%) & 61 & 65 & 126 (70\%) \\
\hline
\end{tabular}


Psoas major width in mid-frontal plane is maximum at L4-5 $(3.34 \pm 0.79 \mathrm{~cm})$ followed by L3-4 $(2.16 \pm 0.78 \mathrm{~cm}), \mathrm{L} 2-3(1.30 \pm 0.61$ $\mathrm{cm})$ and L1-2 $(0.51 \pm 0.52 \mathrm{~cm})$. Psoas major width was more in males than females at all levels with a significant difference ( $p$-value $<0.05$ ) between males and females at all levels. Psoas major width in the mid-frontal plane signifies bulk and strength of muscle. This will decrease the width of the bare window and during surgery more retraction of psoas muscle will be required hence more pressure on the lumbosacral plexus may be exerted.

The bare window is very important for initial docking for either the Jamshidi needle or the first dilator. If there is no bare window available between the major vessels and psoas major vessels, the OLIF procedure will become dangerous with an increased risk of vascular injuries. There is no definite objective measurement available in the literature as to the minimum bare window width required to perform this surgery safely. But arbitrary measurement given is $1 \mathrm{~cm}$ [6]. If we take $1 \mathrm{~cm}$ as an arbitrary window required for performing the procedure then it will not be possible to perform OLIF at L45 in most of the Indian patients, as the average bare window measurement is 0.79 $\mathrm{cm}$ at L45. So, we did a sub-analysis of bare window forming three groups. Group 1 with no space, Group 2 with 0 to $5 \mathrm{~mm}$ of space, and Group 3 with more than $5 \mathrm{~mm}$ space. The rationale being if there is no space or a bare window is ' $0 \mathrm{~cm}$ ' then OLIF cannot be performed. The rationale for using $5 \mathrm{~mm}$ as cut off limit is that majority of the systems available for OLIF have their primary dilator of $5 \mathrm{~mm}$ and if there is sufficient space available for the first dilator to engage then sequential dilators can be used for further widening the space with retraction of the psoas muscle. With this criterion used $10.56 \%$ of patients at L45, $1.12 \%$ patients at L34, $0.56 \%$ patients at L23, and $2.78 \%$ at L12 were in Group 1 where it is not feasible to perform OLIF procedure but in rest, there is sufficient bare window where OLIF can be performed.

We also tried to find out if instead of taking bare window as criteria if the operative window of $1 \mathrm{~cm}$ is taken as criteria then OLIF can be performed after retracting the psoas up to the mid- dle of the vertebral body. Although the cage used for OLIF has no uniform standard and it differs according to the company, its width should be at least $1 \mathrm{~cm}$ [6]. Hence $1 \mathrm{~cm}$ was used so that the cage can be inserted safely after retracting the psoas muscle. In our study, we calculated operative windows $>1 \mathrm{~cm}$ and $<1$ $\mathrm{cm}$. In our study we found operative window is $<1 \mathrm{~cm}$ in $3.33 \%$, $0.55 \%, 0 \%$, and $10.55 \%$ population at L1-2, L2-3, L3-4, and L4-5 levels respectively. All patients have sufficient window at L3-4, and except one, rest all patients have sufficient window at L2-3. But $10.55 \%$ i.e. around 1 in every 10 people do not have sufficient operative window at L4-5.

We used an unpaired t-test to compare the difference between males and females. We found almost all windows at all levels are more in males than females except bare window which is more in females at all levels than males. At L1-2 and L4-5 there was a significant difference ( $p$-value $<0.05)$ between males and females at the vascular window. At L2-3 and L3-4, there was a significant difference ( $\mathrm{p}$-value<0.05) between males and females at the bare window, while at these same levels there was no significant difference for the vascular window. At all levels of psoas major window, there was a significant difference ( $p$-value $<0.05$ ) between males and females.

We compared our results with an imaging anatomical study by Liu et al. [6] on OLIF and found that $6.7 \%$ of people having operative window $<1 \mathrm{~cm}$ [6] at L4-5 level whereas in our study $10.55 \%$ of patients had operative window $<1 \mathrm{~cm}$. We also compared anatomical window at each level with this imaging anatomical study and found that in our study, bare window gradually decreases from L1-L5 both in males and females and minimum at L4-5 whereas in the study by Liu et al. [6] bare window from L1-L5 is maximum at L4-5. We also found that in our study bare window at all levels, females have a bigger bare window, compared to which in the study by Liu et al. [6] males have a larger bare window than females at all levels from L1 to L5.

Comparing our result with the L2-S1 oblique corridor MRI study by Fung et al. [7] and L2-S1 oblique corridor cadaveric

Table 6. Operative window subgroup analysis

\begin{tabular}{lcccccccc}
\hline \multirow{2}{*}{ Levels } & \multicolumn{3}{c}{ Operative window $>1 \mathrm{~cm}$} & & \multicolumn{3}{c}{ Operative window $<1 \mathrm{~cm}$} \\
\cline { 2 - 4 } \cline { 7 - 8 } & Males & Females & Total & & Males & Females & Total \\
\hline L1-2 & 2 & 4 & $6(3.33 \%)$ & & 88 & 86 & $174(96.67 \%)$ \\
L2-3 & 1 & 0 & $1(0.56 \%)$ & & 89 & 90 & $179(99.44 \%)$ \\
L3-4 & 0 & 0 & 0 & & 90 & 90 & $180(100 \%)$ \\
L4-5 & 9 & 10 & $19(10.56 \%)$ & & 81 & 80 & $161(89.44 \%)$ \\
\hline
\end{tabular}


study by Molinares et al. [17], we found that their oblique corridor is similar to our bare window. We also found that in an MRI study by Fung et al. [7], their bare window is more in females than in males at L4-5 and L5-S1 while in our study bare window is more in females than males at all levels. Bare windows in a study by Molinares et al. [17] are decreasing gradually from L2L5 which is similar to our study and the rest of the findings are similar. In the cadaver study of Molinares et al. [17], we found similar results with our study except for their oblique corridor window of males are more than females, while in our study females have more bare windows than men, with the rest of the findings being similar. In the cadaveric study of Molinares et al. [17], values are slightly higher than our values possibly because the cadavers were soaked in formalin and had undergone protein coagulation and tissue retraction. In addition, the structurally American population is taller and bulkier than the Indian population [6].

In our study, the MRI was carried out in a supine position and not in a lateral position. Psoas retraction and a lateral decubitus position are believed to increase the sizes of the corridors [7]. This means that the windows calculated in our study will be smaller but would increase if the study was repeated when the patient is positioned in a lateral position [18]. All aspects of surgery would be easier in thin patients [19]. MIS-OLIF, for levels L2-L5, is a technique that has proven to have encouraging outcomes with good surgical results without major complications [20].

\section{CONCLUSION}

Pre-operative lumbar spine axial MRI evaluation is essential to find out the appropriate selection of a patient for the OLIF procedure. The bare window to perform OLIF gradually decreases from L12 to L45 levels because of the widening of the psoas major window and vascular window from L12 to L45 levels. In the majority of patients at L12, L23, and L34 there is adequate bare window and OLIF can be safely performed in these patients. In $10.56 \%$ of patients' bare window for performing OLIF does not exist at L45 and OLIF may not be feasible in these patients. Indian females have bare windows larger than males at all levels.

\section{CONFLICT OF INTEREST}

No potential conflict of interest relevant to this article.

\section{REFERENCES}

1. Spiker WR, Goz V, Brodke DS. Lumbar interbody fusions for degenerative spondylolisthesis: review of techniques, indications, and outcomes. Global Spine J 2019;9:77-84.

2. Hussain NS, Perez-Cruet MJ. Complication management with minimally invasive spine procedures. Neurosurg Focus 2011;31:E2.

3. Guiot BH, Khoo LT, Fessler RG. A minimally invasive technique for decompression of the lumbar spine. Spine (Phila Pa 1976) 2002;27:432-438.

4. Xu DS, Walker CT, Godzik J, Turner JD, Smith W, Uribe JS. Minimally invasive anterior, lateral, and oblique lumbar interbody fusion: a literature review. Ann Transl Med 2018;6:104.

5. Castellvi AE, Nienke TW, Marulanda GA, Murtagh RD, Santoni BG. Indirect decompression of lumbar stenosis with transpsoas interbody cages and percutaneous posterior instrumentation. Clin Orthop Relat Res 2014;472:1784-1791.

6. Liu L, Liang Y, Zhang H, Wang H, Guo C, Pu X, et al. Imaging anatomical research on the operative windows of oblique lumbar interbody fusion. PLoS One 2016;11:e163452.

7. Fung DA, Diana M, Molinares DM, Timothy T, Davis TT. an MRI study. Spine J 2014;14:S10-S11.

8. Pirró N, Ciampi D, Champsaur P, Di Marino V. The anatomical relationship of the iliocava junction to the lumbosacral spine and the aortic bifurcation. Surg Radiol Anat 2005;27:137-141.

9. Hu WK, He SS, Zhang SC, Liu YB, Li M, Hou TS, et al. An MRI study of psoas major and abdominal large vessels with respect to the X/DLIF approach. Eur Spine J 2011;20:557562

10. Jelev L, Shivarov V, Surchev L. Bilateral variations of the psoas major and the iliacus muscles and presence of an undescribed variant muscle--accessory iliopsoas muscle. Ann Anat 2005;187:281-286.

11. Kepler CK, Bogner EA, Herzog RJ, Huang RC. Anatomy of the psoas muscle and lumbar plexus with respect to the surgical approach for lateral transpsoas interbody fusion. Eur Spine J 2011;20:550-556.

12. Kueper J, Fantini GA, Walker BR, Aichmair A, Hughes AP. Incidence of vascular complications during lateral lumbar interbody fusion: an examination of the mini-open access technique. Eur Spine J 2015;24:800-809.

13. Wang Z, Liu L, Xu XH, Cao MD, Lu H, Zhang KB. The OLIF working corridor based on magnetic resonance imaging: a retrospective research. J Orthop Surg Res 2020;15:141. 
14. Rutter G, Phan K, Smith A, Stewart F, Seex K, Gragnaniello C. Morphometric anatomy of the lumbar sympathetic trunk with respect to the anterolateral approach to lumbar interbody fusion: a cadaver study. J Spine Surg 2017;3:419-425.

15. Julian Li JX, Mobbs RJ, Phan K. Morphometric MRI imaging study of the corridor for the oblique lumbar interbody fusion technique at L1-L5. World Neurosurg 2018;111:e678e685.

16. Davis TT, Hynes RA, Fung DA, Spann SW, MacMillan M, Kwon B, et al. Retroperitoneal oblique corridor to the L2-S1 intervertebral discs in the lateral position: an anatomic study. J Neurosurg Spine 2014;21:785-793.

17. Molinares DM, Davis TT, Fung DA. Retroperitoneal oblique corridor to the L2-S1 intervertebral discs: an MRI study. J
Neurosurg Spine 2016;24:248-255.

18. Zhang F, Xu H, Yin B, Tao H, Yang S, Sun C, et al. Does right lateral decubitus position change retroperitoneal oblique corridor? A radiographic evaluation from L1 to L5. Eur Spine J 2017;26:646-650.

19. Frenkel MB, Hart DJ. Pre-psoas (Oblique) Lateral Interbody Fusion at L5-S1. In: Manjila SV, Mroz TE, Steinmetz MP, editors. Lumbar Interbody Fusions. Edinburgh: Elsevier; 2019. p. 111-119.

20. Ohtori S, Mannoji C, Orita S, Yamauchi K, Eguchi Y, Ochiai N, et al. Mini-open anterior retroperitoneal lumbar interbody fusion: oblique lateral interbody fusion for degenerated lumbar spinal kyphoscoliosis. Asian Spine J 2015;9:565-572. 